US Army Corps of Engineers $s_{\circledast}$

Engineer Research and

Development Center

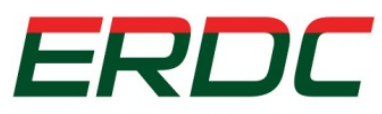

INNOVATIVE SOLUTIONS for a safer, better world

Engineer Site Identification for the Tactical Environment (ENSITE)

\title{
A Framework for Developing Scalable Geodesign Products
}

Elizabeth G. Bastian, Juliana M. Wilhoit, Matthew D. Hiett,

Noah W. Garfinkle; George W. Calfas, Thomas M. Foltz, and

Natalie R. Myers

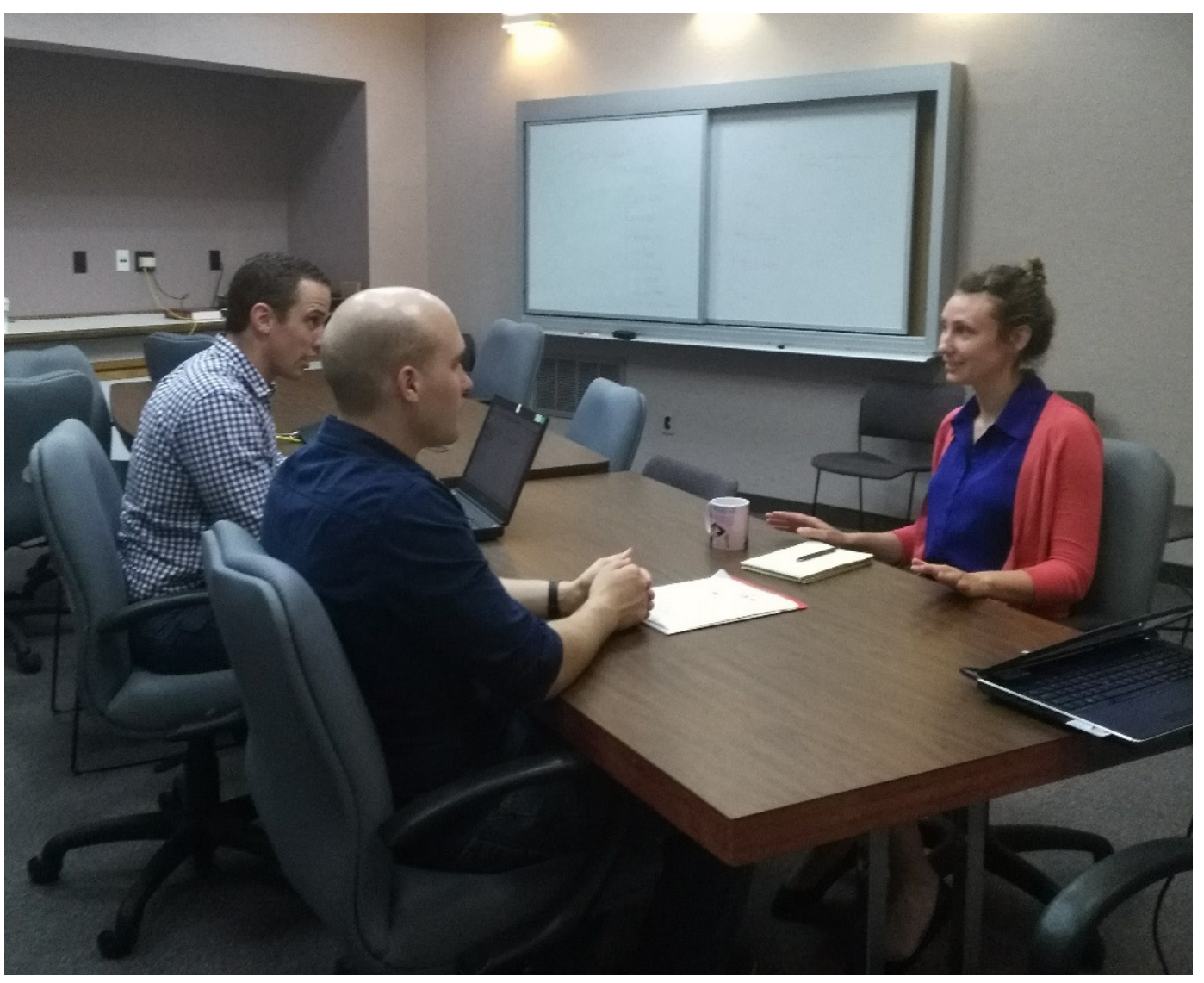


The U.S. Army Engineer Research and Development Center (ERDC) solves the nation's toughest engineering and environmental challenges. ERDC develops innovative solutions in civil and military engineering, geospatial sciences, water resources, and environmental sciences for the Army, the Department of Defense, civilian agencies, and our nation's public good. Find out more at www.erdc.usace.army.mil.

To search for other technical reports published by ERDC, visit the ERDC online library at http://acwc.sdp.sirsi.net/client/default. 


\section{A Framework for Developing Scalable Geodesign Products}

Elizabeth G. Bastian, Juliana M. Wilhoit, Matthew D. Hiett, Noah W. Garfinkle; George W.

Calfas, Thomas M. Foltz, and Natalie R. Myers

Construction Engineering Research Laboratory

U.S. Army Engineer Research and Development Center

2902 Newmark Drive

Champaign, IL 61822

Final report

Approved for public release; distribution is unlimited.

Prepared for Assistant Secretary of the Army for Acquisition, Logistics, and Technology (ASA(ALT))

103 Army Pentagon

Washington, DC 20314-1000

Under Research Program T-45, Project No. 455009, “Contingency Base - Site Identification for the Tactical Environment" 


\section{Abstract}

Geodesign is an urban planning methodology which combines the traditionally separate tasks of landscape planning, site planning, and geographic analysis and combines them through automated software flows. Through combining these elements, a user is able to gain a more complete picture of the operational environment. This paper describes a new geodesign product, ENSITE, which was developed to assist military planners in the siting of contingency bases. This paper outlines the four aspects which made this product successful-a team of diverse subject matter experts, global data, a flexible back end, and rapid development.

DISCLAIMER: The contents of this report are not to be used for advertising, publication, or promotional purposes. Citation of trade names does not constitute an official endorsement or approval of the use of such commercial products. All product names and trademarks cited are the property of their respective owners. The findings of this report are not to be construed as an official Department of the Army position unless so designated by other authorized documents. 


\section{Contents}

Abstract.................................................................................................................................. if

List of Figures...................................................................................................................iv

Preface .............................................................................................................

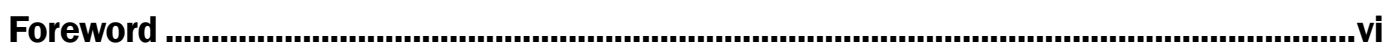

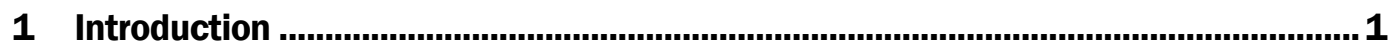

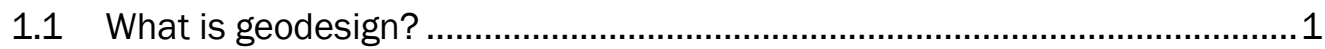

1.2 ENSITE: geodesign for deployed force infrastructure solutions.......................2

1.3 ENSITE's geodesign framework .......................................................... 4

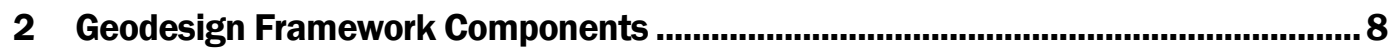

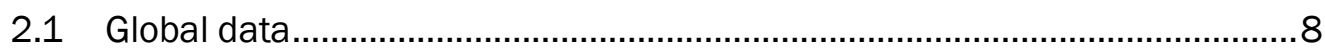

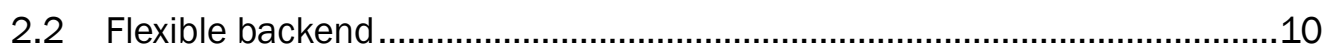

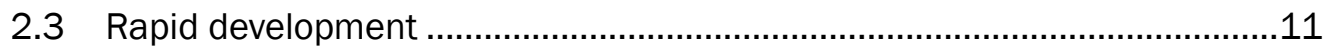

2.4 Team of subject matter experts.............................................................. 13

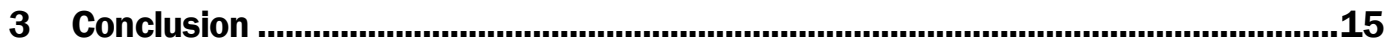

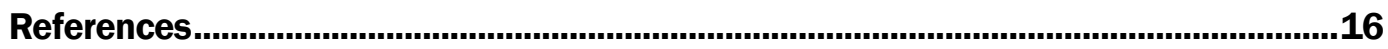

\section{Report Documentation Page}




\section{List of Figures}

\section{Figures}

Figure 1. Two screenshots representing the geodesign software, ENSITE. Figure 1 a demonstrates the multi-criterion decision analysis run for the area of interest.

Figure $1 \mathrm{~b}$ shows a viewshed analysis for one base.

Figure 2. Graphic of iterative design process where questions are asked three times in the creation of a proposal for landscape change (in Wheeler 2012,

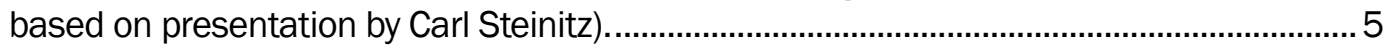

Figure 3. Screenshot of the ArcMap Toolbox for processing data......................................... 9

Figure 4. Members of the ENSITE team strategize a new capability within ENSITE. .........11 


\section{Preface}

This work was conducted for the Department of the Army under applied research program T45, Project 45509, "Contingency Base Site Evaluations for Tactical Environment." The technical monitor was Mr. Kurt Kinnevan, CEERD-CZT.

The work was performed by the Environmental Processes Branch (CNE) of the Installations Division (CN), U.S. Army Engineer Research and Development Center, Construction Engineering Research Laboratory (ERDCCERL). At the time of publication, Mr. Garth Anderson was Chief, CEERDCNE; Ms. Michelle Hanson was Chief, CEERD-CN; and Mr. Kurt Kinnevan, CEERD-CZT, was the Technical Director for Adaptive and Resilient Installations. The Deputy Director of ERDC-CERL was Dr. Kirankumar Topudurti, and the Director was Dr. Ilker Adiguzel.

The Commander of ERDC was COL Bryan S. Green, and the Director was Dr. David W. Pittman. 


\section{Foreword}

The contents of this report represent a version of the authors' paper that was submitted to the ESRI User Conference held in San Diego, California, from 10 July-14 July 2017. The content has not been changed in length or substance, but merely edited for compliance with Engineer Research and Development Center's publishing standards.

Jean S. Noellsch

Writer/Editor (CTR)

Information Science and Knowledge Management Branch

Engineer Research and Development Center 


\section{Introduction}

\subsection{What is geodesign?}

While geodesign is a relatively recent addition to the geographic information systems (GIS) lexicon, the basic concept has been in existence for decades, if not centuries (Miller 2012). According to Carl Steinitz, author of A Framework for Geodesign: Changing Geography by Design, geodesign is not new. Rather, geodesign is a set of concepts and methods derived from both geography and other spatially oriented sciences, as well as from design professions, including architecture, landscape architecture, urban and regional planning, civil engineering, and others (Steinitz 2012).

There is no singular agreed-upon definition of geodesign, though most definitions encapsulate similar ideas and goals of the process. Michael Flaxman, an urban planner, defines geodesign as a “...design and planning method which tightly couples the creation of a design proposal with impact simulations informed by geographic context” (Flaxman 2009, 29). Stephen Ervin, a landscape architect, emphasizes the natural and environmental aspects in his definition while expanding on the modeling capabilities:

Geodesign is environmental design usually involving large areas, complex issues, and multi-person teams, that leverages the powers of digital computing, algorithmic processes, and communications technologies to foster collaborative, information-based design projects, and that depends upon timely feedback about impacts and implications of proposed designs, based on dynamic modeling and simulation, and informed by systems thinking (Ervin 2013).

Taking both of those definitions into consideration, Tess Canfield and Carl Steinitz redefined geodesign as a process which "applies systems thinking to the creation of proposals for change and impact simulations in their geographic contexts, usually supported by digital technology"(Canfield and Steinitz 2014, 1). In sum, by using GIS technologies, geodesign allows for planning and forecasting across scales and among professionals with diverse backgrounds. 
Geodesign, by its nature, is a multidisciplinary, decision-driven process that seeks to leverage geoscience and design practices. Geodesign seeks to elaborate on the "science" aspect of geoscience by extending the analytical role of traditional GIS into a solution production area (Jensen 2011). Through the creation of intuitive and spatially explicit tools and models, geodesign encourages diverse participation in the planning process while lowering the required technical knowledge previously needed to utilize GIS planning tools. The U.S. Army Engineer Research and Development Center (ERDC) has consistently been at the forefront of creating innovative solutions and technologies used by the American fighting force, enabling them to conduct safe and successful operations. This tradition is, in fact, steeped in geodesign. The ERDC-developed open-source GIS tool, GRASS (Geographic Resources Analysis Support System), has been identified as a starting point for computer-aided suitability and geodesign, with its focus on integrating science and geospatial analysis. Goodchild (2010) further identified the framework of funding for GRASS as being a possible way to jumpstart a large-scale geodesign program.

This legacy of geodesign at ERDC continues today, with researchers building decision-driven digital technologies based on a cross-disciplinary approach to GIS and design. ENSITE (Engineer Site Identification for the Tactical Environment) is a multimodal, holistic, software product developed for the military for siting combat infrastructure by utilizing both commercial off-the-shelf software such as ArcGIS ${ }^{*}$ and ENVI ${ }^{\circledR \dagger}{ }^{+}$along with open-source modeling tools such as $\mathrm{R}^{\ddagger}$ and Python. ${ }^{\S} \mathrm{A}$ diverse project team was readily able to translate scientific and engineering processes into spatially-enabled suitability and design tools through a geodesign-based and four-part framework consisting of global data, flexible backend, rapid development, and subject matter expertise.

\subsection{ENSITE: geodesign for deployed force infrastructure solutions}

ENSITE is a desktop software application for assessing the built, natural, and social characteristics of locations for suitability in siting deployed force infrastructure, a phrase which encompasses bases and accompanying

\footnotetext{
* Geographic information system platform developed by Esri of Redlands, California.

$\dagger$ ENVI is an image analysis software designed by the worldwide Harris Corporation.

₹ $\mathrm{R}$ is an open-source language and environment for statistical computing and graphics supported by the R Foundation for Statistical Computing.

$\S$ Open-source software licensed by the nonprofit Python Software Foundation of Beaverton, Oregon.
} 
infrastructure constructed to assist troops in theater (Figure 1). ENSITE strives to be the front end and dashboard for connecting survey and geospatial data for engineer site selection and operation. Developed in agile sprints, there are several innovative and geodesign-related elements which enable ENSITE to provide both survey and geospatial services for users with a wide range of GIS knowledge. These include a map-based user interface, support for integration of prebuilt geospatial tools and workflows, manipulation of data sources into accessible global coverage, and armyspecific data validation and governance processes.

Figure 1. Two screenshots representing the geodesign software, ENSITE. Figure 1a demonstrates the multi-criterion decision analysis run for the area of interest. Figure $1 \mathrm{~b}$ shows a viewshed analysis for one base.

(a)

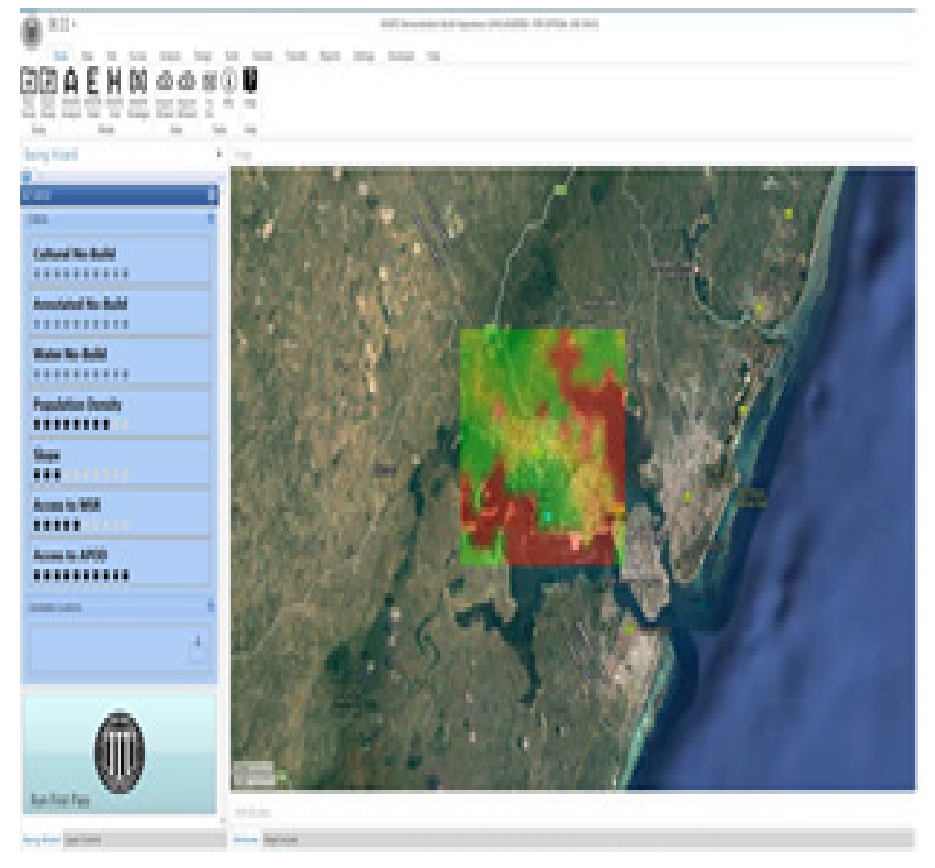


(b)

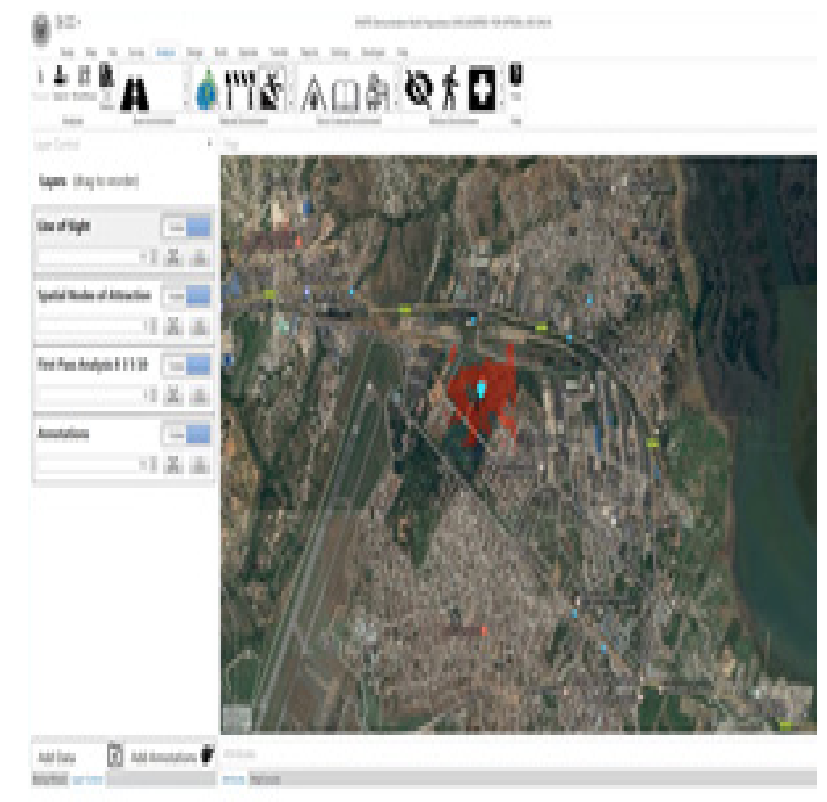

ENSITE is multidisciplinary and holistic in both conception and execution. The program was developed by a research team from ERDC and is sponsored by the Assistant Secretary of the Army for Acquisition, Logistics, and Technology (ASA(ALT)) with a funding timeline of October 2015 to September 2018. In just over a year from the official project start date, ENSITE has already established partnerships and integration processes with several other key operational research projects and programs already in use within the Army. The Virtual Forward Operating Base (VFOB), a computer aided design (CAD)-based program for detailed contingency base camp siting with which ENSITE is interoperable, has allowed a full life cycle of design to happen. Another partner program is Instrument Set, Reconnaissance and Surveying (ENFIRE), a multimodal site reconnaissance suite. These particular partnerships are instrumental in helping ENSITE implement principles of geodesign in the real world.

\subsection{ENSITE's geodesign framework}

In his 2012 book on geodesign, Steinitz puts forth a framework for carrying out geodesign studies, as shown in Figure 2 (Steinitz 2012, 25). Utilizing the efforts of both the geodesign team and relevant stakeholder input, the framework involves three iterative loops through six key questions: the first loop to understand the study area ("why"), the second loop to establish methodology ("how"), and the third loop to actually conduct the study 
("what, " "where," and "when"). Establishing and following such a framework can foster collaboration among science and design professionals, ensure stakeholder inclusion, and provide a platform on which betterinformed, decision-driven results are produced.

Figure 2. Graphic of iterative design process where questions are asked three times in the creation of a proposal for landscape change (in Wheeler 2012, based on presentation by Carl Steinitz).

\section{The geodesign framework - by Carl Steinitz}

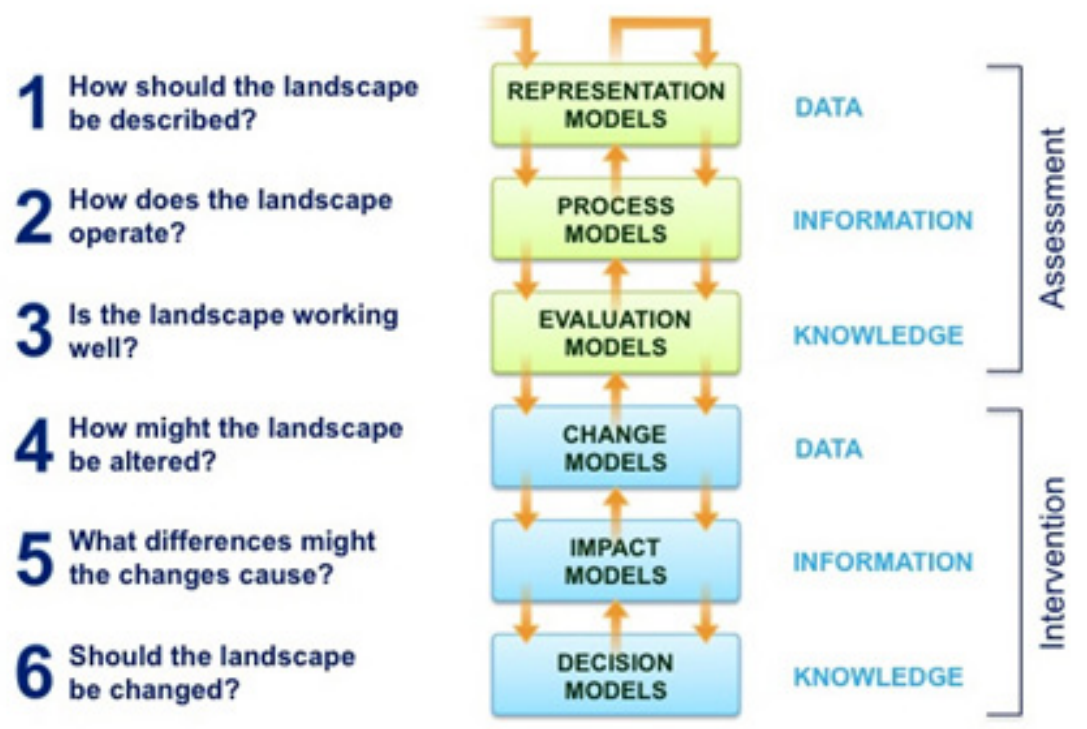

In his own words, Steinitz says the framework may seem "excessively linear," but he notes that the application is rarely linear in practice (Steinitz 2012,33 ). Variations, due to any number of anticipated or unanticipated factors, are to be expected. Since ENSITE was never intended to be a singular study, either in geographical or temporal terms, the Steinitz framework initially seemed almost irrelevant. However, while the ENSITE team may not have followed this framework in the production of the desktop software application, the team desired to provide a program within which users could work through these essential geodesign questions to produce their own suitability and survey studies for specific locations and times. In this way, the ENSITE software is able to walk users through all of Steinitz's steps.

Steinitz believes (and authors here agree) that creativity and invention in geodesign are most successful when well prepared for and applied in a 
clearly organized framework (Steinitz 2012). So while the questions posed and the models utilized in the Steinitz framework became more of a way to determine user workflows, the ENSITE team recognized the need to establish a unique framework to guide the project as a whole, but one that still ensured the incorporation of basic geodesign principles. In order to successfully develop and deploy ENSITE products, a four-part geodesignbased framework was utilized to lead the development process. These framework components are: (1) global data, (2) flexible backend, (3) rapid development, and (4) diverse team of subject matter experts.

As a tool that aims to provide survey and geospatial planning support for any possible operating environment, a basis of global-level data was and is absolutely essential. This data can be scaled from the global level to the regional or local level. The acquisition, governance, and processing of this data is handled within ENSITE HUB, which allows users to create a Mission Folder of datasets that will later be used in decision-making software plug-ins. The Mission Folder is a portable and consistent file structure which remains consistent for each geographic location.

The flexible backend of ENSITE lets developers on the research team write code in multiple languages, and lets users add in additional capabilities according to their existing knowledge base. A flexible backend also eases the integration with other Army programs like VFOB and ENFIRE, enables the use of existing proprietary software, open-source software, and APIs.

One of the cornerstones of the ENSITE development process is the adoption of rapid development. Rather than spending months or years on a feature before putting it in the hands of future users, the team's efforts were concentrated on the rapid development of analysis, followed by user engagement. Rapid development allowed the ENSITE team to quickly pivot and change course as needed.

A team of subject matter experts (SMEs) has been present, both in the members of the research team and in the efforts to incorporate input from current and former Army servicemembers. The research team comprises over 40 researchers with expertise ranging from archeology to coastal management. The team is loosely structured into three subteams for programming, data, and application development. Though diverse, 
these subteams foster collaboration among researchers and have truly propelled the team as a whole to success. 


\section{Geodesign Framework Components}

Determining suitable locations for deployed forces is a multilayer decision process to support the mission and commander's intent. Deployed force infrastructure locations and designs (including base camps) are hardly uniform; each has particular needs ranging from proximity to an airfield to distance to water. Much like Steinitz's six framework questions and accompanying models, ENSITE tools interrogate the landscape progressively through a series of analyses. Analysis begins at a regional level, looking broadly at areas where a user is interested in placing deployed force infrastructure, with the goal of developing an initial suitability map. The scale of this analysis could range from a city to a nation-state. Users are asked to weight a variety of factors, ranging from cultural sites protected by United Nations (UN) conventions to slope. Included factors were chosen based on Army doctrine and feedback from users. Using coarse data (approximately 30 meters) will easily produce an efficient area-specific analysis. The result is a stoplight map (using colors of red, yellow, green), with green indicating the site's suitability for construction based on the weights and factors presented. From these results and localized knowledge, users then are prompted to run an additional series of analyses through plug-ins to gather site-specific information. These analyses range from soil suitability for construction, to flood zones, to viewsheds.

\subsection{Global data}

Global data allows ENSITE to be run for any location on the planet, enabling the software to be tested for many geographic locations and scenarios. While many other geodesign projects are built for a unique planning situation, a specific region (Janssen et al. 2014), or are built to use data produced by the U.S. Census (Nedović-Budić et al. 2006), the range of possibilities that ENSITE software could be used for required developers to rely on globally available data. The necessity of global data creates a challenge for the development of analysis products, as they must also rely on globally available data sources.

To facilitate the global acquisition of data, we developed a series of tools and processes called ENSITE-HUB. HUB empowers users to acquire previously validated datasets relevant to their chosen site geography and timeline, then convert and organize it into a Mission Folder that becomes the backbone of ENSITE analysis. The acquisition and processing of global 
datasets for HUB, with significantly high temporal and spatial resolution, required creative thinking, along with thorough vetting and rigorous testing of datasets. Before data can be included in an analysis within ENSITE, it must be vetted, a process which includes a literature review and approval by the ENSITE Data Governance Committee. ENSITE draws data from both existing open-source and authoritative Army repositories such as the National Geospatial-Intelligence Agency and the Army Geospatial Center. After data is approved for inclusion, a workflow is created on how a user will gain access to the data. For some data sources, this can be accomplished through connecting to an application programming interface (API), while other data sources require filling out a data access request form. Each dataset, and the workflow to access it, are explicitly documented in easy-to-follow steps. Once data is acquired, it is processed through a series of tools to translate the vector data into the Ground-Warfighter Geospatial Data Model (GGDM). As there is no standard for raster naming within the Army, the data are renamed and processed according to schemas specified by the HUB team. To allow for future interoperability between datasets, prefixes for all data were created. For example, an elevation dataset has the name "DEM_" while a landcover dataset starts with the prefix "LC." All data is placed into a Mission Folder, a portable series of folders in which all data have consistent paths, regardless of the geographic location (Figure 3).

Figure 3. Screenshot of the ArcMap Toolbox for processing data.

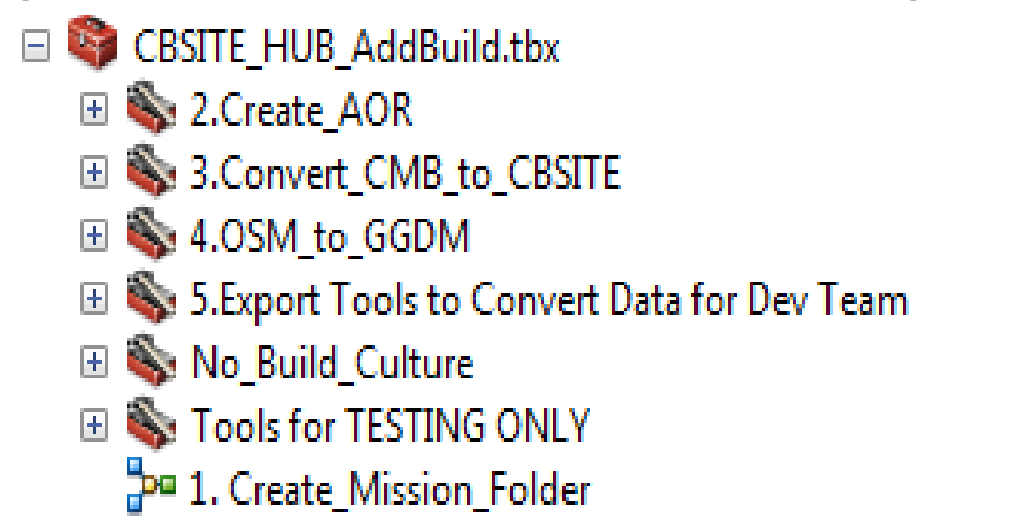

Steinitz's geodesign framework stresses the need to answer all the "why" questions, working through the first and second iterative loops of the framework, before obtaining any data (Steinitz 2012). To Steinitz, this work is critical to ensuring that a geodesign project remains decisiondriven rather than data-driven. As previously stated within the introduction, the ENSITE team did not follow the Steinitz geodesign framework in 
developing the ENSITE software in terms of answering all six questions within the first two loops of the framework. However, not making data acquisition the first step in any project-including ENSITE-in no way lessens the importance of obtaining accurate, timely, and well-documented datasets suitable to the study's goals. The team did ask and answer questions on how ENSITE could change the deployed forces' operational environments before establishing what data was needed to do so. This philosophy was further solidified as the application team developed ideas and prototypes using data that worked to answer their research questions, not caring if it was global in scope. Furthermore, new ideas are constantly developed prior to knowing if there is globally available data. However because of the constraints of using global data, sometimes the availability of data dictates analysis.

Despite defining global data as a crucial component to the ENSITE geodesign framework, global data sets are not sufficient to contextualize the local environment adequately. To plan a base camp, one needs contextual site information such as site soil samples or a site survey. To enable this capacity, ENSITE is interoperable and capable of partnering with ENFIRE. ENFIRE is a technical engineering toolset that is designed to generate, manage, analyze, and digitally distribute a wide variety of engineering data to significantly enhance a number of current and future force command and control requirements. The data collected from ENFIRE follows a consistent schema and is therefore easily integrated into analysis within ENSITE.

\subsection{Flexible backend}

By using an interface that is designed and coded internally, ENSITE has a back end that can process analysis written in a variety of different software languages. The benefit of having a flexible analysis engine is that members of the team can code in a language with which they are comfortable. The programming languages used range from $\mathrm{R}$ and Python to ArcGIS Model Builder. This framework component readily illustrates one of the principles of geodesign by increasing collaboration through reducing the barrier to entry.

As a geodesign platform with a flexible back end, ENSITE is able to interface with other technologies such as CAD (Jensen 2011). The sites identified as possible locations for forward deployed infrastructure can be exported to VFOB, a CAD-based infrastructure planning tool in which a 
base camp is designed. The designs from VFOB can then be fed back into ENSITE for further spatial evaluation, such as line of sight. The flexible back end further allows for data produced to be shared via $\operatorname{ArcSDE}^{\circledR}{ }^{\circledR}$ on the Reachback Engineer Data Integration (REDi) system.

\subsection{Rapid development}

One of the cornerstones of the ENSITE development process is the adoption of rapid development by strategizing new capabilities (Figure 4). Rather than spending months or years on a feature before putting it in the hands of future users, efforts were concentrated on the rapid development of analysis, followed by user engagement. Using ArcGIS Runtime for .NET, a prototype of a stand-alone geospatial analysis platform was developed in a few months' time. This application then allowed the team to test the idea of having a stand-alone program, rather than developing a series of tools to be run in a program like ArcMap.

Figure 4. Members of the ENSITE team strategize a new capability within ENSITE.

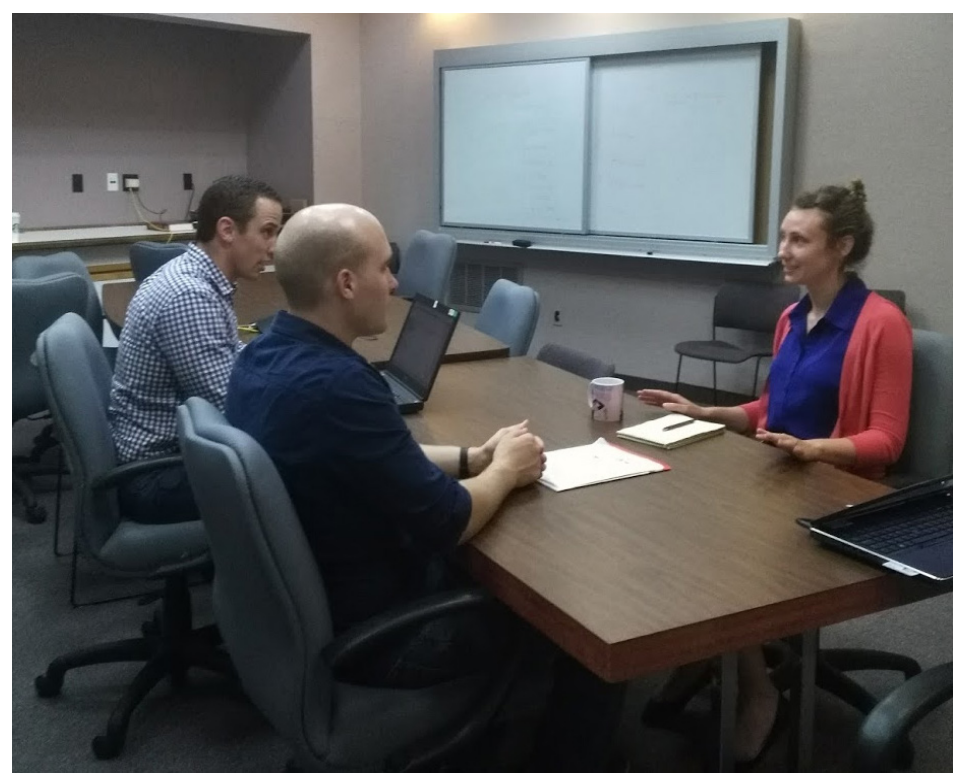

Through engagement with potential users such as members of the 12th Geospatial Planning Cell (GPC), the team was able to identify potential issues with underlying assumptions and workflows. Through this early user engagement, the team was alerted to needed changes; for example, multiple

\footnotetext{
* ArcSDE (Spatial Database Engine) is produced and marketed by Esri of Redlands, California.
} 
locations data were being stored in one database. Furthermore, rapid prototyping demonstrated the need for greater control over ENSITE's user interface and data processing, leading the team to create a custom user interface using Leaflet.js. ${ }^{*}$ This agile development process allowed the team to make the types of crucial pivots described above.

The ENSITE team also applied rapid development principles to the analysis capabilities (plug-ins). For each plug-in, a rapid prototype was developed using the coding language the developer was the most comfortable with-often ESRI Model Builder, but in some instances R or Python. The structure of this rapid development process was led by the following steps:

Step 1. Conceptualize, Research, and Design. All the plug-ins featured in ENSITE were originally identified as necessary capabilities from an end user community. Through interactions with Army stakeholders, ENSITE developers identify a necessary capability, perform the necessary research, and produce a conceptual design for the plug-in. It is important to note that research is a key component to each capability. Members of the team conduct initial research on a capacity and develop an approach towards solving it. This is an iterative process, so a team member may come develop an initial less complicated solution first and then go into a more nuanced solution at a later date.

Step 2. Write Code. The analytical capabilities are then coded to test the concept and its assumptions. This code is written on the platform where the developer has the greatest knowledge and expertise. When developing analytical capabilities, developers must write the code to be compatible with the capabilities of ENSITE's core software. They must also test the code using sample datasets for quality assurance with both the Data and Development teams. This step is often characterized as an iterative testing and debugging phase.

Step 3. Integrate with ENSITE Software. After an individual plug-in developer finishes his/her code and has tested it on sample datasets to ensure the accuracy of the processes, the next step is to fully integrate it within the core-software and perform quality control. The Core-Software

\footnotetext{
* Leaflet an open-source Java Script library for mobile-friendly interactive maps, developed by Vladimir Agafonkin and contributors.
} 
Team handles the majority of the integration, but it is the responsibility of the developer to ensure the analyses meet user expectations.

Step 4. Document. Developers are expected to provide a minimum amount of documentation directly in the code. Additionally, the developer works with the documentation coordinator to maintain accurate records of workflow steps $1-3$. These records not only serve as metadata, but also feed program briefings and technical reports.

\subsection{Team of subject matter experts}

One of the distinctions of the ENSITE team is its core composition of subject matter experts. The ENSITE team comprises over 40 individuals who represent diverse fields such as community planning, forestry, structural engineering, and geography. There is a recognition on the team that no one is able to complete the tasks by relying only on themselves, so it creates a joint ownership in the end product (Brown 2009, 26). Herbert Simon (an American political scientist, economist, sociologist, psychologist, and computer scientist) recognizes this too, discussing the importance of establishing a foundational base for "intellectual endeavor and communication across the arts, sciences and technology" (Foqué 2010, 100). This is core to geodesign-- be it through "multi-person teams" (Ervin 2013) or "collaborative" which the input of people with expertise in different fields and including community stakeholders and the decision makers (Kumar 2012; Steinitz 2012). Planner Paul Zwick specifies that one of his criteria for geodesign is that the process "integrate the design professions with other disciplines-ecology, geography and other earth sciences, real estate, and the social sciences" (Zwick 2010, 10).

This dependency among team members results in a collaborative work environment and overall, a higher-quality production process. Team member diversity has facilitated rapid prototyping, as different individuals have been able to contribute their own unique perspectives and insights into application development while checking assumptions made by others. For example, a Community Planner and Physical Geographer developed a tool for assessing the suitability of land for development by classifying land-use types. Their assessment was based on urban planning principles. However, feedback provided by a structural engineer highlighted an incorrect assumption in their work (Foster 2016). Perhaps the most obvious example of the benefits of geodesign (i.e., bringing together science and design) is 
the ENSITE UI/UX sub-team. The design and development of the user interface and experiences (UI/UX) for ENSITE involved collaborative brainstorming, sketching, and storyboarding sessions between computer scientists, geographers and geoscientists, graphic designers, and anthropologists - not one of whom would be considered an expert in user experience per se, but all of whom had useful contributions to how ENSITE's user community could easily flow through the program.

The deference to and incorporation of SMEs moved beyond the internal workings of the ENSITE team into the larger ERDC and Army organizations through frequent user testing and program demonstrations. Socratically acknowledging the need for input from the deployed forces user community, the ENSITE team attempted to engage former warfighters and enlisted service members to run through all aspects of the ENSITE software, including HUB and Analyst. This effort was supplemented by internal user testing with our integration partner products, such as ENFIRE and VFOB. This ability to easily deliver a series of demonstrable, functioning prototype(s) into the hands of superiors and current Army soldiers/officers is a direct result of the previous three core geodesign framework components. 


\section{Conclusion}

The four-part geodesign framework created and utilized by the ENSITE team has allowed the project to set, meet, and exceed goals within mere months of project kickoff. As of July 2017, ENSITE had developed eight versions of the software, conducted over a dozen user engagement sessions, and partnered with two other major U.S. Army software development programs for deployed forces. Without even one of the four core components of the ENSITE geodesign framework, the project would have been unable to succeed. The ENSITE project is novel, as both a product and a process, not only for the U.S. Army but also for the broader GIS defense solutions community. The diversity present within the program enabled the project to succeed. 


\section{References}

Brown, Tim. 2009. Change by Design: How Design Thinking Transforms Organizations and Inspires Innovation. New York City, NY: HarperCollins Publishers.

Canfield, Tess, and Carl Steinitz. 2014. "Geodesign." Powerpoint presentation at the 4th Geodesign Summit, Redlands, California.

http://www.ce.utexas.edu/prof/maidment/CE365KSpr14/Visual/Shearer.pdf.

Ervin, Stephen M. 2013. “What Makes It 'Geodesign'?” The Field (blog). August 22. https://thefield.asla.org/2013/08/22/what-makes-it-geodesign/.

Flaxman, Michael. 2009. "Fundamentals of Geodesign." In Digital Design in Landscape Architecture 2009, 28-41, proceedings of the $10^{\text {th }}$ International Conference on Information Technologies in Landscape Architecture, held 21-23 May 2009 at Anhalt University of Applied Sciences, University of Malta. Available at: http://www.kolleg.loel.hsanhalt.de/landschaftsinformatik/fileadmin/user_upload/_temp_/2010/Proceedings/Buhmann 28-41.pdf

Foqué, Richard. 2010. Building Knowledge in Architecture. Chicago, IL: Independent Publishers Group, ASP-VUB Press.

Foster, Kelleann. 2016. "Geodesign Parsed: Placing It within the Rubric of Recognized Design Theories." Landscape and Urban Planning 156: 92-100.

Goodchild, Michael F. 2010. "Towards Geodesign: Repurposing Cartography and GIS?” Cartographic Perspectives,no. 66: 7-22.

Janssen, Ron, Tessa Eikelboom, Jos Verhoeven, and Karlijn Brouns. 2014. "Using Geodesign to Develop a Spatial Adaptation Strategy for Friesland.” In GeoJournal Library, 103-16.

Jensen, Meika. 2011. "What Is Geodesign? GIS Lounge.” GIS Lounge. September 30. https://www.gislounge.com/what-is-geodesign/.

Kumar, Vijay. 2012. 101 Design Methods: A Structured Approach for Driving Innovation in Your Organization. Indianapolis, IN: John Wiley \& Sons.

Miller, William R. 2012. "Introducing Geodesign: The Concept.” Esri white paper, available at: https://www.esri.com/library/whitepapers/pdfs/introducing-geodesign.pdf.

Nedović-Budić, Zorica, Raymond G. Kan, Douglas M. Johnston, Richard E. Sparks, and David C. White. 2006. "CommunityViz-Based Prototype Model for Assessing Development Impacts in a Naturalized Floodplain-EmiquonViz." Journal of Urban Planning and Development 132(4): 201-10.

Steinitz, Carl. 2012. A Framework for Geodesign: Changing Geography by Design. Redlands, CA: Esri Press. 
Wheeler, Carla. 2012. "Geodesign Gathers Momentum: Two-Day GeoDesign Summit Focuses on Geodesign Technologies and Practices." ArcWatch: GIS News, Views and Insights, February. http://www.esri.com/news/arcwatch/0212/geodesign-gathersmomentum.html.

Zwick, Paul. 2010. “The World beyond GIS.” Planning 76(6): 20-23. 


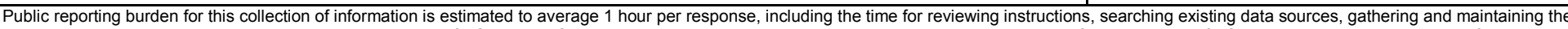

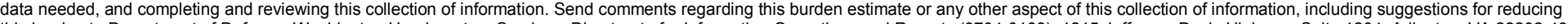

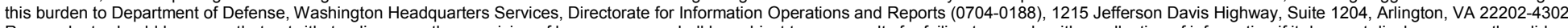

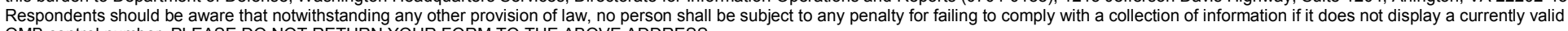
OMB control number. PLEASE DO NOT RETURN YOUR FORM TO THE ABOVE ADDRESS.
1. REPORT DATE (DD-MM-YYYY)
September 2017
2. REPORT TYPE

\section{Final}
3. DATES COVERED (From - To)

\section{TITLE AND SUBTITLE}

A Framework for Developing Scalable Geodesign Products 5a. CONTRACT NUMBER

5b. GRANT NUMBER

5c. PROGRAM ELEMENT NUMBER

$\mathrm{T} 45$

5d. PROJECT NUMBER

45509

5e. TASK NUMBER

5f. WORK UNIT NUMBER

8. PERFORMING ORGANIZATION REPORT NUMBER

ERDC/CERL MP-17-3

\section{Construction Engineering Research Laboratory (CERL)}

U.S. Army Engineer Research and Development Center (ERDC)

PO Box 9005

Champaign, IL 61826-9005

\section{SPONSORING / MONITORING AGENCY NAME(S) AND ADDRESS(ES)}

Assistant Secretary of the Army for

Acquisition, Logistics, and Technology

103 Army Pentagon

Washington, DC 20314-1000

10. SPONSOR/MONITOR'S ACRONYM(S)

ASA(ALT)

11. SPONSOR/MONITOR'S REPORT NUMBER(S)

12. DISTRIBUTION / AVAILABILITY STATEMENT

Approved for public release. Distribution is unlimited.

\section{SUPPLEMENTARY NOTES}

\section{ABSTRACT}

Geodesign is an urban planning methodology which combines the traditionally separate tasks of landscape planning, site planning, and geo-graphic analysis and combines them through automated software flows. Through combining these elements, a user is able to gain a more complete picture of the operational environment. This paper describes a new geodesign product, ENSITE, which was developed to assist military planners in the siting of contingency bases. This paper outlines the four aspects which made this product successfula team of diverse subject matter experts, global data, a flexible back end, and rapid development.

\section{SUBJECT TERMS}

Geographic information systems (GIS), City planning, Military bases-- Design and construction, ENSITE

\section{SECURITY CLASSIFICATION OF:}

a. REPORT

Unclassified

\section{b. ABSTRACT}

Unclassified

\begin{tabular}{|} 
17. LIMITATION \\
OF ABSTRACT \\
UU
\end{tabular}

18. NUMBER OF PAGES

26 19a. NAME OF RESPONSIBLE PERSON

19b. TELEPHONE NUMBER (include area code) 